\title{
ANALISIS KINERJA BUNDARAN JOEANG DI KOTA PALANGKA RAYA PROVINSI KALIMANTAN TENGAH
}

\author{
Erik Strada $^{1}$, Salonten ${ }^{2}$ dan Murniati ${ }^{3}$ \\ ${ }^{123}$ Program Studi Teknik Sipil, Fakultas Teknik, Universitas Palangka \\ Raya E-mail: stradaerik114018@gmail.com ${ }^{1}$, salonten@jits.upr.ac.id ${ }^{2}$ \\ dan murniatity@gmail.com ${ }^{3} /$ HP.+6282148471065 ${ }^{1}$
}

\begin{abstract}
ABSTRAK
Bundaran Joeang merupakan salah satu bundaran yang ada di Kota Palangka Raya yang dilewati oleh kendaraan yang keluar dan masuk kota maupun pergerakan kendaraan dalam kota. Kondisi daerah sekitar Bundaran Joeang mengakibatkan terjadinya arus lalu lintas perjalanan yang cukup besar karena adanya perkantoran, perumahan, sekolah, taman, rumah jabatan dan berbagai aktifitas olahraga. sehingga dilakukan analisis kinerja Bundaran Joeang terhadap pergerakan arus lalu lintas.Penelitian ini bertujuan untuk mengetahui besarnya arus lalu lintas yang melewati bundaran tersebut terutama pada saat jam-jam sibuk, kinerja bundaran pada saat ini maupun yang akan datang menggunakan acuan (MKJI) 1997. Hasil analisis menunjukkan bahwa bagian jalinan Bundaran Joeang tahun 2021 memiliki nilai arus bagian jalinan yang terbesar yaitu $677 \mathrm{smp} / \mathrm{jam}$, jalinan DA (Jalan Letkol Chr. Binti-Jalan Seth Adjhi), kapasitas terbesar jalinan DA (Jalan Letkol Chr. Binti -Jalan Seth Adjhi), 5,177 smp/jam, derajat kejenuhan tertinggi dari jalinan CD (Jalan Seth Adjhi-Jalan Letkol Chr. Binti) 0,158, tundaan lalu lintas bundaran rata-rata $\left(\mathrm{DT}_{\mathrm{R}}\right) 1,85 \mathrm{det} / \mathrm{smp}$, tundaan bundaran rata-rata (DR) $5,85 \mathrm{det} / \mathrm{smp}$, karakteristik tingkat pelayanan pada kondisi sekarang adalah kelas A. Hasil perhitungan proyeksi 10 tahun akan datang berdasarkan pertumbuhan kepemilikan kendaraan terjadi peningkatan dimana untuk nilai arus bagian jalinan yang terbesar pada jalinan CD (Jalan Seth Adjhi-Jalan Letkol Chr. Binti) 4.276 smp/jam, Kapasitas terbesar lengan DA (Jalan Letkol Chr. Binti -Jalan Seth Adjhi) $7.087 \mathrm{smp} / \mathrm{jam}$, tingkat pelayanan menurun dari kategori A pada tahun 2021 menjadi kategori B tahun 2031.
\end{abstract}

Kata Kunci : Jalinan, Bundaran, Derajat Kejenuhan, Tundaan, Tingkat Pelayanan.

\section{ABSTRACT}

Joeang Roundabout is one of the roundabouts in Palangka Raya City angpassed by vehicles in and out of the city as well as the movement of vehicles in the city. Condition area around Joeang Roundabout resulted in a considerable flow of travel traffic due to the presence of offices, housing, schools,parks, office houses and berlike sports activities. This study aims to find out the amount of traffic flow that passes through the roundabout, especially during peak, roundabout performance at this time and in the future using the reference (MKJI) 1997. The results of the analysis showed 
JURNAL KACAPURI

JURNAL KEILMUAN TEKNIK SIPIL

Volume 4 Nomor 1 Edisi Juni 2021

that the intertwining part Roundabout Joeang in 2021 has the largest interwoven part current value of $677 \mathrm{smp} / \mathrm{h}$, intertwined DA (Sreet Letkol Chr. Binti-Sreet Letkol Chr. Adjhi), 5,177 smp/h, the highest degree of saturation of the CD braid (Sreet Seth Adjhi-Sreet Letkol Chr. Binti) 0.158, average roundabout traffic delay $\left(D T_{R}\right) 1.85 \mathrm{sec} / \mathrm{smp}$, average roundabout delay (DR) $5.85 \mathrm{det} / \mathrm{smp}$, service level characteristics in current condition is class A. Projected calculation results of 10 years to come based on the growth of vehicle ownership there is an increase where for the value of the largest interwoven section flow on the CD interwoven (Sreet Seth AdjhiSreet Letkol Chr. Binti) 4. $276 \mathrm{smp} / \mathrm{h}$, Largest capacity of DA arm (Sreet Letkol Chr. Binti - Sreet Seth Adjhi) 7,087 smp/h, service level decreased from category A in 2021 to category B in 2031.

Keywords: : Braid, Roundabout, Degree of Saturation,Delay, Service Level.

\section{PENDAHULUAN}

Transportasi merupakan salah satu kebutuhan bagi kehidupan masyarakat modern, pemanfaatan teknologi yang berkembang dengan pesat serta laju pertumbuhan penduduk yang semakin meningkat dari tahun ke tahun mengakibatkan kebutuhan akan transportasi semakin tinggi, Kota Palangka Raya sendiri yang merupakan Ibukota Provinsi Kalimantan Tengah yang mengalami perkembangan yang cukup pesat. Kota Palangka Raya memiliki luas wilayah $2400 \mathrm{~km}^{2}$ dan berpenduduk sebanyak 283.612 jiwa dengan kepadatan penduduk rata-rata 2067 jiwa tiap $\mathrm{km}^{2}$.Perkembangan yang begitu pesat harus diikuti pula dengan penerapan sistem lalu lintas yang efektif dan efisien bagi pelayanan terhadap setiap pergerakan penduduk, pengaturan sistem transportasi ini diharapkan akan tercapainya tingkat efektifitas dan efesiensi yang baik terhadap segi biaya maupun manfaat dan waktu. Pengaturan ini perlu didukung dengan fasilitas jalan, jenis dan tebal perkerasan serta pendukung lainnya seperti trotoar, lampu lalu lintas, marka jalan dan sebagainya. Pada persimpangan biasanya pengaturan arus lalu lintas menggunakan rambu-rambu lalu lintas, lampu lalu lintas dan taman bundaran. Bundaran adalah salah satu bentuk pertemuan jalan yang berfungsi sebagai pengontrol pembagi dan pengaruh sistem lalu lintas berputar satu arah.dalam perencanaan bundaran selain segi geometris seperti bentuk ukuran/dimensi perlu diperhatikan pula volume lalu lintas yang akan melewati bundaran tersebut.Bundaran Joeang salah satu bundaran yang ada di Kota Palangka Raya, Provinsi Kalimantan Tengah. Bundaran ini melayani arus ruas jalan Seth Adjhi Kota Palangka Raya, karena kondisi tata guna lahan daerah sekitar yang akan terjadinya bangkitan dan tarikan perjalanan yang cukup besar karena adanya perkantoran, perumahan, sekolah, taman, rumah jabatan dan berbagai aktifitas olahraga di bundaran tersebut. Bundaran Joeang mempunyai nilai lebih karena dapat mempersingkat akses menuju ke Bandar Udara Tjilik Riwut. Dengan jenis alat transfortasi yang bervariasi seperti sepeda motor, mobil, dan kendaraan berat, sehingga diperlukan proyeksi arus lalu lintas kedepannya untuk 
mengetahui apakah bundaran tersebut dapat memenuhi kebutuhan dari arus kendaraan. Bundaran Joeang adalah salah satu dari lima bundaran yang ada di Kota Palangka Raya Provinsi Kalimantan Tengah.

\section{Rumusan Masalah}

Berdasarkan latar belakang yang telah dijelaskan, maka dapat dirumuskan permasalahan pada penelitian ini sebagai berikut:

1. Berapa volume lalu lintas yang melewati Bundaran Joeang Kota Palangka Raya?

2. Bagaimana kinerja Bundaran Joeang Kota Palangka Paya ?

3. Bagaimana kinerja bundaran dalam melayani arus lalu lintas pada 10 tahun yang akan datang?

\section{Batasan Masalah}

Untuk memberikan hasil yang optimal, maka perlu adanya pembatasan masalah dalam penelitian ini antara lain sebagai berikut :

1. Lokasi penelitian berada pada Bundaran Joeang Kota Palangka Raya .

2. Pengumpulan data lapangan dilakukan selama 7 hari pada jam puncak, yaitu pada Pagi hari (06.00-08.00 WIB), pada Siang hari (12.00-14.00 WIB), dan pada Sore hari (15.00-17.00 WIB), dan dilakukan survey satu hari penuh pada hari pertama selama 12 jam untuk mengetahui jam sibuk pada bundaran tersebut.

3. Dasar perhitungan menggunakan metode Manual Kapasitas Jalan Indonesia 1997.

\section{Tujuan Penelitian}

Tujuan dari penelitian ini antara lain:

1. Mengetahui volume lalu lintas yang melewati Bundaran Joeang.

2. Mengetahui Kinerja Bundaran Joeang tersebut.

3. Mengetahui kemampuan bundaran dalam melayani arus lalu lintas pada 10 tahun yang akan datang.

\section{Manfaat Penelitian}

Dari penelitian ini diharapkan diperoleh manfaat antara lain :

1. Memberikan informasi dan sebagai bahan pertimbangan bagi instansi terkait dalam memperbaiki sistem manajemen lalu lintas, baik dalam tingkat pertumbuhan lalu lintas maupun karakteristik dasar lalu lintas.

2. Memberi alternatif sebagai solusi untuk mengatasi masalah yang berhubungan dengan kemampuan bundaran dalam melayani arus lalu lintas untuk masa-masa yang akan datang.

\section{TINJAUAN PUSTAKA}

\section{Persimpangan (Intersection)}

Persimpangan adalah suatu daerah umum dimana dua arus jalan atau lebih bergabung atau berpotongan, termasuk fasilitas-fasilitas yang ada di pinggir jalan untuk pergerakan lalu lintas pada daerah tersebut. (Morlok,1991). 
Secara garis besar, persimpangan terbagi dalam dua bagian, yaitu persimpangan sebidang dan persimpangan tidak sebidang.

\section{Bundaran}

Bundaran berfungsi sebagai pengontrol pembagi dan pengaruh sistem lalu lintas berputar satu arah. Tujuan utama bundaran adalah melayani gerakan yang menerus, namun hal ini tergantung dari kapasitas dan luas daerah yang dibutuhkan. (Hobbs, 1995)

Tipe bundaran berdasarkan MKJI 1997 terbagai atas berbagai macam, seperti yang terlihat pada Tabel 1 .

Tabel 1. Tipe Bundaran

\begin{tabular}{cccccc}
\hline $\begin{array}{c}\text { Tipe } \\
\text { Bundaran }\end{array}$ & $\begin{array}{c}\text { Jari-Jari } \\
\text { Bundaran } \\
(\mathrm{m})\end{array}$ & $\begin{array}{c}\text { Jumlah } \\
\text { Lajur } \\
\text { Masuk } \\
(\mathrm{m})\end{array}$ & $\begin{array}{c}\text { Lebar } \\
\text { Lajur } \\
\text { Masuk } \\
(\mathrm{m})\end{array}$ & $\begin{array}{c}\text { Panjang } \\
\text { Jalinan }\end{array}$ & $\begin{array}{c}\text { Lebar } \\
\text { Jalinan }\end{array}$ \\
\hline R10 - 11 & 10 & 1 & 3,5 & 23 & 7 \\
R10 - 22 & 10 & 2 & 7,0 & 27 & 9 \\
R14 - 22 & 14 & 2 & 7,0 & 31 & 9 \\
R20 - 22 & 20 & 2 & 7,0 & 43 & 9 \\
\hline
\end{tabular}

Sumber : MKJI, 1997

\section{Kapasitas Jalinan Bundaran}

Kapasitas bundaran dapat didefinisikan sebagai banyaknya kendaraan yang dapat ditampung oleh jalan tersebut dalam waktu tertentu. Kapasitas total bagian jalinan bundaran adalah hasil perkalian antara kapasitas dasar (Co) dan faktor koreksi (F), dengan memperhitungkan pengaruh kondisi lapangan sesungguhnya terhadap kapasitas. (MKJI,1997).

Untuk menghitung kapasitas pada bundaran, dapat menggunakan rumus sebagai berikut (MKJI,1997):

$\mathrm{C}=135 \times \mathrm{WW}^{1,3} \times\left(1+\mathrm{W}_{\mathrm{E}} / \mathrm{W}_{\mathrm{W}}\right)^{1,5} \times\left(1-\mathrm{P}_{\mathrm{W}} / 3\right)^{0,5} \times\left(1+\mathrm{W}_{\mathrm{W}} / \mathrm{LW}_{\mathrm{W}}\right)^{-1,8} \times \mathrm{F}_{\mathrm{CS}} \mathrm{x}$

$\mathrm{F}_{\mathrm{RSU}}$

Faktor penyesuain $\mathrm{F}_{\mathrm{CS}}$ untuk ukuran kota berdasarkan padajumlah penduduk kota sebagaimana pada Tabel 2.

Tabel 2. Faktor Penyesuaian Ukuran Kota

\begin{tabular}{ccc}
\hline Ukuran Kota (CS) & Penduduk (juta) & $\begin{array}{c}\text { Faktor Penyesuaian } \\
\text { Ukuran Kota (Fcs) }\end{array}$ \\
\hline Sangat kecil & $<0,1$ & 0,82 \\
Kecil & $0,1-0,5$ & 0,88 \\
Sedang & $0,5-1,0$ & 0,94 \\
Besar & $1,0-3,0$ & 1
\end{tabular}




\begin{tabular}{ccc} 
Sangat besar & $>3,0$ & 1,05 \\
\hline
\end{tabular}

Sumber : MKJI,1997

\section{Volume Lalu Lintas}

Volume lalu lintas adalah satuan pengukuran jumlah arus lalu lintas yang ditunjukkan oleh jumlah kendaraan atau jumlah penggunaan jalan yang melewati suatu titik pengamatan dalam satuan waktu, baik dalam hari, jam, dan menit (Hobbs, 1995)

Data lalu lintas dibagi dalam beberapa tipe kendaraan yaitu kendaraan ringan (LV), kendaraan berat (HV), sepeda motor (MC) dan kendaraan tak bermotor (UM). Arus lalu lintas tiap pendekat dibagi dalam tipe pergerakan, antara lain: gerakan belok kanan (RT), belok kiri (LT), dan lurus (ST). Arus lalu lintas ini kemudian dikonversi dari kendaraan per jam menjadi satuan mobil penumpang (smp) dengan menggunakan ekuivalen mobil penumpang (emp) dengan nilai LV:1,0; HV:1,3 dan MC:0,5.

\section{Derajat Kejenuhan}

Kinerja lalu lintas merupakan ukuran pelayanan lalu lintas yang diperoleh oleh pengguna jalan. Salah satu ukuran kinerja lalu lintas adalah derajat kejenuhan. Derajat kejenuhan bagian jalinan dapat dihitung sebagai berikut (MKJI,1997):

$\mathrm{DS}=\mathrm{Q} / \mathrm{C}$

dimana $\mathrm{Q}$ adalah arus total dan $\mathrm{C}$ adalah kapasitas

\section{Tundaan Bagian Jalinan Bundaran}

\section{Tundaan Lalu Lintas Bagian Jalinan (DT)}

Tundaan Lalu Lintas Bagian adalah tundaan rata-rata lalu lintas per kendaraan yang masuk ke bagian jalinan. Tundaan lalu lintas ditentukan dari hubungan antara tundaan lalu lintas dan derajat kejenuhan, yang di tentukan dengan persamaan berikut (MKJI,1997):

$$
\mathrm{DT}=2+(2,68982 \times \mathrm{DS})-(1-\mathrm{DS}) \times 2 \text {; }
$$

untuk DS $\leq 0,6$

$$
\mathrm{DT}=\frac{1}{(0,59186-0,52525 \times \mathrm{DS})}-(1-\mathrm{DS}) \mathrm{X} 2 \text {; }
$$

untuk DS $>0,6$

\section{Tundaan Lalu Lintas Bundaran (DTR)}

Tundaan lalu lintas bundaran adalah tundaan rata-rata per kendaraan yang masuk kedalam bundaran. Dihitung sebagai berikut (MKJI,1997):

DTR $=\Sigma($ Qi x DTi) / Qmasuk 
Dimana $\mathrm{Q}_{\mathrm{i}}$ adalah arus total pada bagian jalinan I, DTi adalah tundaan lalu lintas rata-rata pada bagian jalinan i dan Qmasuk yaitu jumlah arus yang masuk bundaran (smp).

\section{Tundaan Bundaran (DR)}

Tundaan bundaran adalah tundaan lalu lintas rata-rata per kendaraan masuk bundaran dan dihitung sebagai berikut (MKJI,1997):

$\mathrm{D}_{\mathrm{R}}=\mathrm{DT}_{\mathrm{R}}+4$

Dimana $\mathrm{D}_{\mathrm{R}}$ adalah tundaan bundaran, dan $\mathrm{DT}_{\mathrm{R}}$ adalah tundaan lalu lintas bundaran.

\section{Peluang Antrian Bagian Jalinan}

Peluang antrian dihitung dari hubungan antara peluang antrian dengan derajat kejenuhan, yang dihitung menggunakan persamaan berikut (MKJI,1997):

$$
\begin{aligned}
\mathrm{QP} \% \min = & (9,41 \times \mathrm{DS})+\left(29,967 \times \mathrm{DS}^{4,619}\right) \\
\mathrm{QP} \% \text { maks }= & (26,65 \times \mathrm{DS})-\left(55,55 \times \mathrm{DS}^{2}\right)+ \\
& \left(108,57 \times \mathrm{DS}^{2}\right) \ldots \ldots \ldots \ldots \ldots \ldots \ldots \ldots \ldots \ldots \ldots \ldots \ldots \ldots
\end{aligned}
$$

\section{Tingkat Pelayanan}

Tingkat pelayanan adalah perbedaan kondisi operasional yang terjadi pada suatu jalan sewaktu jalan tersebut melayani berbagai macam volume lalu lintas. Untuk mendapatkan kinerja suatu bundaran perlu dilakukan perhitungan derajat kejenuhan dan tundaan lalu lintas bundaran. Tingkat pelayanan dikategorikan dari yang terbaik (tingkat pelayanan A) sampai yang terburuk (tingkat pelayanan F).(Tamin, 2000).

\section{Perhitungan Pertumbuhan Lalu Lintas dan Penduduk}

Untuk menghitung pertumbuhan arus 10 tahun yang akan datang, digunakan rumus pendekatan (bunga berganda) yang menggunakan data masukan berupa data jumlah penduduk, serta jumlah kepemilikan kendaraan bermotor, yang dinyatakan dalam persamaan berikut ini (Suwadi,2004):

$$
\operatorname{Pn}=\operatorname{Po}(1+\mathrm{i})^{\mathrm{n}}
$$

\section{METODE PENELITIAN}

\section{Lokasi Penelitian}

Penelitian ini berlokasi di Kota Palangka Raya, Kalimantan Tengah tepatnya di Bundaran Joeang. Bundaran ini melayani arus lalu lintas dari berbagai arah, yaitu Jalan Seth Adjhi, Jalan Strowberry Raya dan Jalan Letkol Chr. Binti.

\section{Pengumpulan Data}


Data yang digunakan untuk dianalisa didapat dengan cara pengumpulan data primer dan data sekunder sesuai dengan kebutuhan penelitian. Metode pengumpulan data yang dilakukan adalah sebagai berikut:

\section{Data Primer}

Data Primer merupakan data yang didapatkan secara langsung dilapangan atau pada lokasi penelitian.

Pengumpulan data primer untuk analisa data yaitu sebagai berikut:

a. Data geometrik bundaran yaitu pengumpulan data yang dilakukan dengan mengadakan observasi terhadap kondisi geometrik bundaran yang meliputi diameter bundaran, lebar pendekat $\left(\mathrm{W}_{1}\right)$ dan $\left(\mathrm{W}_{2}\right)$, lebar jalinan (Ww), panjang jalinan (Lw)

b. Data volume lalu lintas yaitu pengumpulan yang dilakukan dengan cara mengelompokkan jenis kendaraan yang lewat.

c. Kondisi lingkungan yaitu dengan melihat langsung di lokasi penelitian untuk menentukan tipe lingkungan jalan berupa kawasan permukiman, komersial, atau akses terbatas dan kelas hambatan samping.

\section{Data Sekunder}

Data sekunder merupakan data yang diperoleh dari instansi terkait atau berwenang dalam penyediaan data yang berhubungan dengan masalah yang menjadi objek penelitian. Data sekunder tersebut meliputi jumlah penduduk di kota Palangka Raya, jumlah kepemlikan kendaraan di Kota Palangkaraya, peta lokasi dan dokumentasi.

\section{Waktu Penelitian}

Penelitian ini dilaksanakan selama 1 (satu) minggu, pada hari pertama penelitian dilakukan selama 12 (dua belas) jam untuk menentukan jam sibuk penelitian pada hari berikutnya yaitu jam sibuk selama dua jam pada pagi hari, siang hari, dan sore hari.

\section{HASIL ANALISIS DAN PEMBAHASAN}

\section{Geometrik Bagian Jalinan}

Data mengenai ukuran (panjang dan lebar) jalinan pada lokasi Bundaran Joeang yang diukur dalam $\mathrm{m}$ (meter).

Tabel 3. Ukuran Geometrik

\begin{tabular}{llllll}
\hline $\begin{array}{l}\text { Bagian } \\
\text { jalinan }\end{array}$ & $\left(\mathbf{W}_{\mathbf{1}}\right)$ & $\left(\mathbf{W}_{\mathbf{2}}\right)$ & $\left(\mathbf{W}_{\mathbf{E}}\right)$ & $\left(\mathbf{W}_{\mathbf{w}}\right)$ & $\left(\mathbf{L w}_{\mathbf{w}}\right)$ \\
\hline $\mathrm{AB}$ & 13,70 & 24,10 & 18,90 & 12,70 & 77,00 \\
$\mathrm{BC}$ & 7,00 & 14,00 & 10,50 & 12,50 & 73,30 \\
$\mathrm{CD}$ & 12,50 & 25,40 & 18,95 & 12,80 & 76,30 \\
$\mathrm{DA}$ & 6,20 & 16,50 & 11,35 & 12,60 & 80,50 \\
\hline
\end{tabular}




\section{Volume Lalu Lintas}

Dari hasil survei selama 7 hari, diperoleh volume kendaraan terbesar pada hari Selasa Pukul 15.30-16.30 WIB, yaitu sebesar $1.873 \mathrm{smp} / \mathrm{jam}$, dimana arus bagian jalinan AB yaitu $304 \mathrm{smp} / \mathrm{jam}$, jalinan BC sebesar $313 \mathrm{smp} / \mathrm{jam}$, jalinan CD adalah $677 \mathrm{smp} / \mathrm{jam}$, serta jalinan DA yaitu $600 \mathrm{smp} / \mathrm{jam}$.

\section{Kapasitas}

Berdasarkan hasil analisis perhitungan menggunanakan metode Manual Kapasitas Jalan Indonesia 1997, diperoleh nilai kapasitas seperti pada Tabel 4 di bawah ini.

Tabel 4. Kapasitas Jalinan Bundaran

\begin{tabular}{ccccc}
\hline $\begin{array}{c}\text { Bagian } \\
\text { jalinan }\end{array}$ & $\begin{array}{c}\text { Kapasitas } \\
\text { dasar }(\mathrm{Co}) \\
\text { smp/jam }\end{array}$ & $\begin{array}{c}\text { Faktor Penyesuaian } \\
\text { Ukuran kota } \\
\left(\mathrm{F}_{\mathrm{CS}}\right)\end{array}$ & $\begin{array}{c}\text { Lingkungan } \\
\text { jalan }\left(\mathrm{F}_{\mathrm{RSU}}\right)\end{array}$ & $\begin{array}{c}\text { Kapitas } \\
\text { smp/jam }\end{array}$ \\
\hline $\mathrm{AB}$ & 5.212 & 0,88 & 0,940 & 4.311 \\
$\mathrm{BC}$ & 6.269 & 0,88 & 0,940 & 5.168 \\
$\mathrm{CD}$ & 5.195 & 0,88 & 0,940 & 4.297 \\
$\mathrm{DA}$ & 6.258 & 0,88 & 0,940 & 5.177 \\
\hline
\end{tabular}

Sumber : Analisis Data (2021)

\section{Perilaku Lalu Lintas}

Hasil analisis perhitungan menggunanakan metode Manual Kapasitas Jalan Indonesia 1997, diperoleh nilai derajat kejenuhan dan tundaan lalu lintas jalinan tertinggi pada jalinan CD sebesar 0,158 dan 0,74 det/smp dan Bundaran Joeng memiliki nilai tundaan lalu lintas bundaran rata-rata sebesar 1,85 det/smp dan peluang antrian sebesar 1,5\%-5,5\%. Hasil analisis perilaku tiap jalinan pada Tabel dibawah ini.

Tabel 5. Hasil Analisis Bagian Jalinan Bundaran pada Tahun 2021

\begin{tabular}{|c|c|c|c|c|c|c|c|}
\hline \multirow{2}{*}{$\begin{array}{l}\text { Bagian } \\
\text { Jalinan }\end{array}$} & \multirow{2}{*}{$\begin{array}{c}\text { Arus } \\
\text { Bagian } \\
\text { Jalinan } \\
\text { Q } \\
\text { smp/jam }\end{array}$} & \multirow{2}{*}{$\begin{array}{c}\text { Kapasitas } \\
\text { C } \\
\text { smp/jam }\end{array}$} & \multirow{2}{*}{$\begin{array}{c}\text { Derajat } \\
\text { Kejenuhan } \\
\text { DS }\end{array}$} & \multirow{2}{*}{$\begin{array}{c}\text { Tundaan Lalu } \\
\text { Lintas } \\
\text { DT } \\
\text { det/smp }\end{array}$} & \multirow{2}{*}{$\begin{array}{c}\text { Tundaan Lalu } \\
\text { Lintas Total } \\
\text { DT }_{\text {TOT }} \\
\operatorname{det} / \text { smp }\end{array}$} & \multicolumn{2}{|c|}{$\begin{array}{c}\text { Peluang Antrian } \\
\text { QP\% }\end{array}$} \\
\hline & & & & & & Min & Max \\
\hline $\mathrm{AB}$ & 304 & 4.311 & 0,071 & 0,33 & 100 & 0,6 & 2,2 \\
\hline $\mathrm{BC}$ & 313 & 5.168 & 0,061 & 0,28 & 87 & 0,6 & 1,8 \\
\hline
\end{tabular}


$\mathrm{CD}$

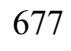

0,74

500

1,5 5,5

DA

600

5.177

0,116

0,54

324

1,1

3,9

DS dari jalinan

0,158

Total

1011

Tundaan lalu-lintas bundaran rata -rata $\mathrm{DT}_{\mathrm{R}}$ det/smp

1,85

Tundaan bundaran rata -rata DR $\left(\mathrm{DT}_{\mathrm{R}}+4\right)$ det/smp

5,85

Peluang antrian bundaran $\mathrm{QP}_{\mathrm{R}} \%$

1,5

Sumber : Hasil Analisis (2021)

\section{Proyeksi Kondisi Bundaran 10 Tahun Yang Akan Datang}

Untuk memprediksi kondisi bundaran pada 10 tahun yang akan datang digunakan data pertumbuhan rata-rata kepemilikan kendaraan untuk memprediksi pertumbuhan lalu lintas dan kapasitas jalinan untuk 10 tahun yang akan datang dianggap tetap atau sama pada kondisi geometrik tahun 2021. Hasil analisis perhitungan untuk proyeksi 10 tahun yang akan datang terdapat pada tabel di bawah ini.

Tabel 6. Hasil Analisis Bagian Jalinan Bundaran pada Tahun 2031

\begin{tabular}{|c|c|c|c|c|c|c|c|}
\hline \multirow{2}{*}{$\begin{array}{l}\text { Bagian } \\
\text { Jalinan }\end{array}$} & \multirow{2}{*}{$\begin{array}{c}\text { Arus } \\
\text { Bagian } \\
\text { Jalinan } \\
\text { Q } \\
\text { smp/jam }\end{array}$} & \multirow{2}{*}{$\begin{array}{c}\text { Kapasitas } \\
\text { C } \\
\text { smp/jam }\end{array}$} & \multirow{2}{*}{$\begin{array}{c}\text { Derajat } \\
\text { Kejenuhan } \\
\text { DS }\end{array}$} & \multirow{2}{*}{$\begin{array}{l}\text { Tundaan } \\
\text { Lalu } \\
\text { Lintas } \\
\text { DT } \\
\text { det/smp }\end{array}$} & \multirow{2}{*}{$\begin{array}{c}\text { Tundaan } \\
\text { Lalu Lintas } \\
\text { Total } \\
\text { DT } \\
\text { det } / \text { smp }\end{array}$} & \multicolumn{2}{|c|}{$\begin{array}{c}\text { Peluang } \\
\text { Antrian } \\
\text { QP\% }\end{array}$} \\
\hline & & & & & & Min & Max \\
\hline $\mathrm{AB}$ & 2.399 & 6.417 & 0,374 & 1,75 & 4.198 & 3,8 & 17,4 \\
\hline $\mathrm{BC}$ & 2.618 & 6.423 & 0,408 & 1,91 & 5.000 & 4,3 & 19,7 \\
\hline $\mathrm{CD}$ & 4.276 & 6.357 & 0,673 & 3,53 & 15.094 & 11.1 & 41,9 \\
\hline DA & 4.203 & 7.087 & 0,593 & 2,78 & 11.684 & 8,3 & 34,4 \\
\hline \multicolumn{3}{|c|}{ DS dari jalinan } & 0,673 & Total & 35.976 & & \\
\hline \multicolumn{5}{|c|}{ Tundaan lalu-lintas bundaran rata -rata $\mathrm{DT}_{\mathrm{R}}$ det/smp } & 5,40 & & \\
\hline \multicolumn{5}{|c|}{ Tundaan bundaran rata - rata DR $\left(\mathrm{DT}_{\mathrm{R}}+4\right) \mathrm{det} / \mathrm{smp}$} & 9,40 & & \\
\hline \multicolumn{6}{|c|}{ Peluang antrian bundaran $\mathrm{QP}_{\mathrm{R}} \%$} & 11,1 & 41,9 \\
\hline
\end{tabular}

\section{PENUTUP}

\section{Kesimpulan}

Berdasarkan hasil analisis dan perhitungan, maka dapat disimpulkan sebagai berikut: : 
1. Arus lalu lintas pada Bundaran Joeang Kota Palangka Raya pada masing-masing bagian jalinan, yaitu AB (Jalan Seth Adjhi-Jalan Seth Adjhi) sebesar 304 smp/jam, jalinan BC (Jalan Strawberry Raya-Jalan Seth Adjhi) sebesar $313 \mathrm{smp} / \mathrm{jam}$, jalinan CD (Jalan Seth Adjhi-Jalan Letkol Chr. Binti) sebesar $677 \mathrm{smp} / \mathrm{jam}$ dan jalinan DA (Jalan Letkol Chr. Binti-Jalan Seth adjhi) sebesar $600 \mathrm{smp} / \mathrm{jam}$. Arus bagian jalinan yang tertinggi yaitu pada jalinan AB (Jalan Seth Adjhi-Jalan Strawberry Raya) dan arus bagian jalinan yang terendah pada jalinan DA (Jalan Letkol Chr. Binti-Jalan Seth Adjhi).

2. Kapasitas pada Bundaran Joeang Kota Palangka Raya di masingmasing bagian jalinan, yaitu AB (Jalan Seth Adjhi-Jalan Strawberry Raya) sebesar 4.311 smp/jam, BC (Jalan Strawberry Raya-Jalan Strawberry Raya) sebesar $5.168 \mathrm{smp} / \mathrm{jam}, \mathrm{CD}$ (Jalan Seth Adjhi-Jalan Letkol Chr. Binti) sebesar $4.297 \mathrm{smp} / \mathrm{jam}$, dan DA (Jalan Letkol Chr. Binti-Jalan Seth Adjhi) sebesar 5.177 smp/jam. Kapasitas bagian jalinan yang terbesar terletak pada bagian jalinan AB (Jalan Seth AdjhiJalan Strawberry Raya) dan yang terkecil terletak pada bagian jalinan CD (Jalan Seth Adjhi-Jalan Letkol Chr. Binti). Nilai derajat kejenuhan tertinggi dari jalinan CD (Jalan Seth Adjhi-Jalan Letkol Chr. Binti) adalah 0,158 , tundaan lalu lintas bundaran rata-rata $\left(\mathrm{DT}_{\mathrm{R}}\right)$ yaitu 1,85 det/smp, dan tundaan bundaran rata-rata (DR) yaitu 5,85 det/smp, serta peluang antrian sebesar 1,5\%-5,5\%. Sehingga dapat disimpulkan bahwa Bundaran Joeang memiliki karakteristik tingkat pelayanan pada kondisi sekarang adalah kelas A.

3. Hasil perhitungan proyeksi 10 tahun yang akan datang yakni pada tahun 2031 berdasarkan pertumbuhan kepemilikan kendaraan, maka Bundaran Joeang Kota Palangka Raya memiliki arus lalu lintas pada masing-masing bagian jalinan, yaitu AB (Jalan Seth Adjhi-Jalan Strawberry Raya) sebesar $2.399 \mathrm{smp} / \mathrm{jam}$, jalinan BC (Jalan Strawberry Raya-Jalan Seth Adjhi) sebesar $2.618 \mathrm{smp} / \mathrm{jam}$, jalinan CD (Jalan Seth Adjhi -Jalan Letkol Chr. Binti) sebesar $4.276 \mathrm{smp} /$ jam dan jalinan DA (Jalan Letkol Chr. Binti - Jalan Seth Adjhi) sebesar 4.203 smp/jam. Arus bagian jalinan yang tertinggi yaitu pada jalinan CD (Jalan Seth Adjhi -Jalan Letkol Chr. Binti) dan arus bagian jalinan yang terendah pada jalinan AB (Jalan Seth Adjhi-Jalan Strawberry Raya). Kapasitas terbesar pada lengan DA (Jalan Letkol Chr. Binti -Jalan Seth Adjhi) yaitu $7.087 \mathrm{smp} / \mathrm{jam}$, dengan nilai derajat kejenuhan dari jalinan CD (Jalan Seth Adjhi -Jalan Letkol Chr. Binti) adalah 0,673, tundaan lalu lintas bundaran rata-rata $\left(\mathrm{DT}_{\mathrm{R}}\right)$ yaitu $5,40 \mathrm{det} / \mathrm{smp}$, dan tundaan bundaran rata-rata (DR) yaitu 9,40 det/smp, serta peluang antrian sebesar 11,1\%-41,9\%. Sehingga dapat disimpulkan bahwa Bundaran Joeang pada tahun 2031 memiliki karakteristik tingkat pelayanan menurun dari tahun 2021 yaitu tingkat pelayanan pada kelas A. Untuk 10 tahun yang akan datang kondisi bundaran masih dalam kategori $\mathrm{B}$ (Dalam zona arus stabil, pengemudi memiliki kebebasan yang cukup untuk memilih kecepatannya) dan belum memerlukan lampu lalu lintas.

\section{Saran}


Berdasarkan kesimpulan yang diperoleh dari hasil penelitian, maka dapat diberikan beberapa saran sebagai berikut:

1. Perlu adanya penambahan pemasangan rambu lalu lintas (rambu hatihati).

2. Perlu diadakan sosialisasi oleh instansi terkait kepada masyarakat tentang lalu lintas, karena masih banyak pengendara di jalan raya yang belum mengerti tentang rambu-rambu lalu lintas.

3. Perlu adanya penertiban oleh instansi terkait pada lengan bundaran dan jalinan bundaran, karena banyak terdapat kendaraan orang yang sedang berolahraga yang parkir tidak pada tempat nya.

\section{DAFTAR PUSTAKA}

1. Alamsyah, A. (2005), Rekayasa Lalu Lintas, Universitas Muhammadiyah Malang, Malang.

2. Direktorat Jendral Bina Marga (1997), Manual Kapasitas Jalan Indonesia (MKJI), Sweroad Bekerjasama dengan PT.Bina Karya, Jakarta.

3. Hobbs, F.D (1995), Perencanaan dan Teknik Lalu Lintas, Gadjah Mada University Press, Yogyakarta.

4. Kurniawan, R, (2013), Analisis Kemampuan Bundaran KB Kota Sampit Dalam Melayani Arus Lalu Lintas. Tugas Akhir Fakultas Teknik Universitas Palangka Raya. Palangka Raya.

5. Morlok, E. K, (1991), Pengantar Teknik dan Perencanaan Transportasi, Erlangga, Jakarta.

6. Mulyawan, S. H, (2010), Analisis Kemampuan Bundaran Dalam Melayani Arus Lalu Lintas. (Studi Kasus Bundaran Dharma Wanita Kota Buntok). Tugas Akhir Fakultas Teknik Universitas Palangka Raya, Palangka Raya.

7. Sudjana. (1991), Metode Statistika, Tarsito, Bandung.

8. Transportation Research Board (2006), Highway Capacity Manual, TRB Special Report, Washington D.C. 